\title{
Discussion on Types of Decoration Function
}

\author{
Shen Tao \\ Hezhou University \\ Hezhou, Guangxi, China \\ E-mail: bclb7372@sina.Com
}

\begin{abstract}
People have never been separated from decoration since human began to do creation activities. Comparing with space and volume, decoration is also related to functions and is applied in all aspects of human creation activities, although it is rarely studied or valued. It is impossible for us to express functions groundlessly and abstractly, and the embodiment of a design function is always realized by the use of specific materials, the form of design structure and the final visible artifacts. Decoration is an important symbol of human creation activities, and it implies the profound human culture information; like space and volume, it also displays the material structure of the world and the cognitive structure of human beings.
\end{abstract}

Keywords-Decoration; Function; Type of decoration
function

\section{INTRODUCTION}

It is always believed that the purpose of artifact decoration is the non-functional aesthetic creation, and functionalists think that decoration is a kind of superfluous and useless waste of energy. But in fact, as long as we connect the artifacts and the pursuit of beauty, the influence of decoration on creatures is everywhere, and the so-called "pure form" is an abstract decorative form. Our interpretation for the function of any historical artifact cannot exclude the influence of decoration factors as decoration also has bright and complete form of expression like space and volume. Therefore, with continuous improvement of material and spiritual civilization, decoration is permeating into everywhere of design field in an unprecedented way, resulting in more and more extensive changes in our way of life.

\section{CONCEPT OF DECORATION}

Both "Ornament" and "Decoration" have the meaning of embellishment in English, and the two words have the same meaning in Chinese, but the specific meanings are different in English. "Ornament" originally means "articles for increasing the beauty of something", and it is from the old French "ornement" and Latin "ornare"; ornament means something organic that is growing out, and refers to a necessary part in the structure of something. The word of "decorate" appeared in the 17 th century at the earliest in the West, and it generally means art decoration; except the meaning of decoration, it also has the meaning of "adding something to a place to make it more attractive" and is used more extensively than ornament. "Decoration" means something that is irrelevant to the main structure and is added to play a favorable role. Or decoration is the pattern and shape used for adding the visual beauty without changing the main structure of an artifact, such as the sculpture and floriation in buildings or lace or edging of handicrafts. In China, the word of “装饰” appeared in the 5th century, with the meaning of dressing up or making up. It is stated in History of the Latter-Han Dynasty - Biography of Liang Hong that:

"Women are requested to make cloth gowns and hemp shoes and knit tools such as basket. When they get married, they decorate to get in." [1]. In ancient China, the word of “纹 饰” or “文饰” has the same meaning with modern “decoration", and “文” means decorations on people' s body, with the extended meaning of adorning and beautifying. The extended meaning was extensive and profound in the spring and autumn. “文” means highly cultured and gentle men. In Origin of Chinese Characters, “饰” means brushing. It is also written as “拭” in Chinese characters. It means wiping dust on the artifact for brightening.

\section{MEANING OF FUNCTION}

"Function" means role, purpose, assembly, duty or mathematical function in English. "Function" was originally a biological concept and referred to the organism, especially the "role or movement of cell tissue or organ (mechanism)". When "function" is used with the meaning of "purpose", it strictly means the favorable role of a thing or method. "Decoration" means the embellishment that is irreverent to the main structure and is added to play a favorable role. It is thus obvious that both "decoration" and "function" have the meaning of "playing a favorable role" . In China, the word of “功能” has two concepts. "功” means "function". The original meaning of “功” is making some achievements. The word consists of two parts, namely, “エ” and “力”, and it means striving to accomplish an undertaking. It is stated in Mencius •Gong Sun Chou I that: "Master, if you were to obtain the ordering of the government in $\mathrm{Qi}$, could you promise yourself to accomplish anew such results as those realized by Guan Zhong and Yan? [2]. it is stated in Xunzi · On Heaven that: "We cannot see the working process of all things, but we can see the achievements of them." [3]. the word means "achievement" here. “能” has the original meaning of mythical creatures such as bear, it is stated in Ren Fang' s A Wonder Book and Tanglewood Tales that: "The animal is called bear in land and is called “能” in water" . It also has the meaning of "ability" . It is stated in Laozi · Tao Te Ching 
that: "A man finds no competitors in this world." and

"There is no one is the world who is able to know and able to practice them." [4].

\section{TYPES OF DECORATION FUNCTION}

The function of decoration shows a structural feature both in building and artifact design. It is said that "The production of decorative pattern is because of the functional needs, that is, decorative pattern is formed or transformed into with functional needs, and the pattern has the functions of reinforcement, anti-skidding, opening and indicating." [5]. the function of decoration also shows different hierarchies, that is, the hierarchy of decoration can determine the expression form of function. If the most superficial coating, painting, decorative pattern and sculpture are more structured, the expression of deep structure of function is greater. Meanwhile, the cultural significance of decoration is more profound. In such fields with decoration as the culture, the function types of decoration can be divided into the following categories: utility function, aesthetic function, social function, symbol function, folk function, regulating function and emphasis function.

\section{A. Utility function}

Seeing from decorations of artifacts handed down from the ancient times, each decoration has the specific intended use and purpose. "So decoration shall be based on the function at present and originally." [6]. In the Warring States period, Mo $\mathrm{Zi}$ proposed that " $\mathrm{A}$ thing is artful if it is useful, and the thing is clumsy if it is useless", and the statement fully indicates the opinion that decoration function is subject to utility. For example, furniture in the Ming Dynasty is vey scientific in term of dynamics, and Ming Dynasty furniture with graceful structure and decorations remarkably shows that the modernism design language highlights the principles of utility, economy and conciseness. Of course, function is not the single aspect, and the excessive pursuit of function will result in loss of many important design contents. Some contents are not included in the concept of function, and the material and spirit contents and the respective primary and secondary position are changed with time and different products. The utility function in the material sense is increasingly unable to represent the expression of emotional appeal.

\section{B. Aesthetic function}

Decoration in ancient times had the guiding principle of utility, combining the formal beauty of people's habit in appreciation. This principle that "utility is beautiful" was determined by the social productivity development level at that time, and it objectively promoted the formation and normalization of decorations. For design, production and use of artifacts, except that the utility shall meet people's demand for comfort, the sense of beauty and joviality of human senses and spirits shall be realized. Providing visual and spiritual aesthetics and pleasure for people is also a spiritual function, therefore, utility is not enough, and an artifact must be beautiful; the value of artifact shall also include the value of beauty. For Chinese ancient artifacts, the unification of utility and beauty was noted by people in pre-Qin times, and the unification of "utility" and "beauty" is actually the unification of "form" and "content", that is, "balance of outward grace and solid worth" proposed by Confucius. Therefore, the unification of utility and beauty has become the basic characteristics and design pursuit of artifacts in all ages.

\section{Social function}

Decoration had close relationship with the primitive religion, witchcraft and totem in early times, but its social utility and practicability continuously increased with continuous development of society. For example, the social function of clothing has been identification from the beginning of human history. People use the clothing mark to prove the tribe of them. Then decorations of clothing became the sign of hierarchy after the tribe members' sense of hierarchy appeared. Standards for decorations in all aspects including clothing, food, housing and transportation are systematically specified in Etiquette and Book of Rites, and the sign of hierarchy is embodied in decorations for artifacts in daily life, room environment as well as various sacrifice ceremonies and rituals and clothing and dressing. The decorative pattern, color and modeling are the obvious features of hierarchical power and authority, and the stronger artistry and the more exquisite technology of decorations are, the more prestigious the owner's power and status are. From the perspective of politics, the focus of decorations was developed by ideology, and the functions of social hierarchy and class consciousness can be embodied naturally in utility function.

\section{Symbol function}

Decoration has become the symbol of culture with its aesthetic form and social function, and through the appreciation for ornamentations of cultural relics, people can read the belief, morality, technical and emotional information of that era as many decorations can be understood as the historical information code of era. So cultural anthropologists always discover and grasp the internal features of symbol information such as different national cultures and history from different decorations. After the essential value of use function of a certain ancient artifact is lost, the decorative forms of order, line, form and color have important cultural value and new art significance. Decorations of artifacts further extend and enrich the image connotation of artifacts, and make artifacts become the symbolic product beyond the utility function rather than decoration in the pure sense. Therefore, it is believed that the decoration form of objective is a need of symbolization of artifacts, and it constructs the new expression function that conveying information at cultural and spiritual level except the utility function of artifacts.

\section{E. Folk function}

The folk style of decorations reflects the way of thinking and value orientation of people in different nationalities, contains strong national emotion and national psychology, and it is the extension of the working people's labor life and consciousness form. In form, comparing with the complication and gorgeousness of court decorations, folk decorations pursue a kind of natural beauty of approximately primitive form. Craftsmen can apply the "ingenuity" in each artifact at will, so most folk artifacts are not identical, and the decoration and 
innovation techniques are novel and unique. The decoration combines the working people's good wishes and everything in nature, and fully displays the simple design thought and the natural beauty of modeling. Meanwhile, under the influence of the traditional Confucian culture and the control of thinking consciousness of "unity of heaven and man", folk decorations permeate the idea of "people oriented". Folk decoration is not only expressed as the exterior pattern but also has the internal deep meanings and functions, and it is based on the folk custom and tradition; decoration has more profound significance and utility purpose.

\section{F. Regulating function}

Firstly, decoration plays the role of adjusting the appearance of design and coordinating the proportional relation between part and the whole. Secondly, for both ancient decorations and modern decorations, decoration plays the role of enhancing the physical properties of artifacts and adjusting the comprehensive utilization effect of artifacts. For design of artifacts, the decorativeness and utility of the structure are each other's restriction and correction, and decorations give full play to such regulating function. Thirdly, the innovation regulated by decorations can accordingly change the shape of artifacts, and such change has obvious influence on the application; an exquisite decoration can be formed after people creatively process the defective or faulty materials. The word of "whitewashing" means that decoration has the functions of making up and regulating defects of materials, and the regulating function is the core guidance method for decorating and processing some rare and precious materials.

\section{G. Emphasis function}

Because of the strong representation characteristics of decorations, the change of decoration form will result in the continuous improvement of visual experience reflection. "The form of decoration, so to speak, adapts and accumulates the feeling experience of human vision for form, and it stimulates and satisfies human's feeling with the form and symbol of beauty," [7]; decoration is used for emphasizing the function of volume or space, and different types of artifacts have different emotions and artistic features. However, the emphasis for decoration function must be reasonable, and suitability is an important criterion for decoration. If an artifact is excessively sculptured or embellished, the too cumbersome decoration is improper and will destroy and weaken the essential beauty. It is stated in Rites of the Zhou •Winter Official •Artificers' Record that: "The weather is limited by season, and the land is limited by climate; there are good or bad materials, and there are skillful and clumsy craftsmen." The statement that "there are good or bad materials" refers to the essential and natural beauty of a certain material, and such beauty is also the natural performance characteristics of different materials. By emphasizing the structure and decoration, materials are burnished and sublimed, and such burnish and sublimation are the brilliant points of the emphasis function of decoration.

\section{CONCLUSIONS}

Overall, as a traditional artistic idea, decoration is closely linked to the social and cultural environment as well as economic and technology development. The trend decorative art emerged in the 20th century promotes the subsequent development of decorative art, and a large number of various new technologies and new materials are integrated into the decorative art, promoting the expressive force and the diversified development direction of decoration. Further, the research perspective of decoration is deeply transformed from the traditional techniques into the modern design. With continuous improvement of material and spiritual civilization at present, people are more strongly pursuing beauty, and application of decoration will be more extensive. Although the historical decorative art limits the people's comprehensive and deep survey because of the remote origin and huge contents, and many explanations for decoration fail to be agreed on, decoration has been developed vigorously in the distant history, and with the development of high technology, globalization and informatization, decoration will be shown to the world for maintaining the national features with the diversified form and the concept of sustainable development.

\section{ACKNOWLEDGMENT}

Postal address: School of Design, Hezhou University, No. 18 Xihuan Road, Hezhou City, Guangxi Zhuang Autonomous Region 542899. Email: bclb7372@sina.com, Tel: 15841297952 .

Author: Shen Tao (1965 - ), male, born in Anshan, Liaoning, is a professor of School of Design in Hezhou University in Guangxi Zhuang Autonomous Region. He is engaged in sculpture and study of art design.

\section{REFERENCES}

[1] (Song period of the Southern Dynasties) Compiled by Fan Ye, annotated by Li Xian et al (Tang Dynasty). Volume 83 of History of the LatterHan Dynasty, No. 73 of "Biography of Hermits", [M]. Beijing: Zhonghua Book Company. 2012-12: 2765

[2] Translated and annotated by Wan Lihua and Lan Xu. Chinese Classic Collection - Mencius. [M]. Beijing: Zhonghua Book Company. 2006-09: 50

[3] Simple Annotation for Collection of Xunzi's Works. Written by Liang Qixiong.[M]. Beijing: Zhonghua Book Company. 1983-01: 220

[4] [Wei] Annotated by Wang Bi. Collated by Lou Yulie. Annotation and Collation of Laozi Tao Te Ching [M]. Beijing: Zhonghua Book Company. 2008-12: 169+175

[5] Written by Tian Zibing, Wu Shusheng and Tian Qing. The History of Chinese Decorative Pattern. [M]. Beijing: China Education Press: 200311: 2

[6] Written by Tian Zibing, Wu Shusheng and Tian Qing. The History of Chinese Decorative Pattern. [M]. Beijing: China Education Press: 200311: 20

[7] Li Yanzu. Hundred-year History of Modern Art and Significance of Decoration [J]. Literature and Art Studies. 5th issue in 1996: 111-131. 